\title{
Liver Resection Combined with Local Ablation: Where Are the Limits?
}

\author{
Koert P. de Jong Marieke W.J.L.A.E. Wertenbroek \\ Department of Hepato-Pancreato-Biliary Surgery and Liver Transplantation, University Medical Center Groningen, \\ University of Groningen, Groningen, The Netherlands
}

\section{Key Words}

Liver tumor - Thermoablation - Partial hepatectomy •

Neoadjuvant chemotherapy

\begin{abstract}
Background/Aims: Partial hepatectomy for liver tumors is potentially curative but unfortunately available only for a limited number of patients. Local tumor destruction by ablation has expanded criteria for treatment and potential cure for patients with liver tumors. This paper gives an overview of the possibilities and limitations of ablation of liver tumors. Methods: A search of relevant peer-reviewed literature was conducted. Results: Investigations in the second half of the 18th century paved the way for application of electromagnetic fields in living organisms. Currently, indications for thermoablation are (1) unresectable liver tumors, (2) bridging therapy for a more definitive treatment, (3) debulking of symptomatic hormonally active liver tumors, and (4) patients unfit for major abdominal procedures. Although randomized trials on the use of radiofrequency ablation (RFA) are scarce, the results thus far suggest that the combination of partial liver resection and local ablation offers cure rates in the same order of magnitude as partial liver resection the 'gold standard' - alone. Additionally, RFA seems to be associated with a lower morbidity and mortality rate as com-
\end{abstract}

pared to partial liver resection. One of the disadvantages is the reported high incidence of ablation site recurrences of sometimes up to $30 \%$. This is especially related to a larger size of ablated tumors and tumors close to large vessels. Also, RFA is a rather time-consuming procedure. On theoretical grounds, ablation with microwaves is more effective and faster and seems to be associated with a lower incidence of ablation site recurrences. Conclusions: Ablation has acquired a place in the arsenal of treatment modalities for patients with liver tumors and expanded the indications for treatment with a curative intent. Further evolution of the technique and the proof that it has at least the same oncological result with a lower morbidity as partial hepatectomy are required in the near future.

Copyright $\odot 2011$ S. Karger AG, Basel

\section{Introduction}

Partial liver resection is an established therapy for patients with liver tumors. In patients with liver metastases from colorectal cancer, partial hepatectomy is a potentially curative treatment in about $30-50 \%$ of the patients. Whereas in the early days of liver surgery for colorectal liver metastases criteria for liver resection were rather strict, it became progressively clear that

\section{KARGER}

Fax +4161306 1234

E-Mail karger@karger.ch

www.karger.com
(C) 2011 S. Karger AG, Basel

$0253-4886 / 11 / 0282-0127 \$ 38.00 / 0$

Accessible online at:

www.karger.com/dsu
Koert P. de Jong, MD, PhD

Department of Hepato-Pancreato-Biliary Surgery and Liver Transplantation

University Medical Center Groningen, University of Groningen

NL-9700 RB Groningen (The Netherlands)

Tel. +31 50361 2896, E-Mail k.p.de.jong@ chir.umcg.nl 
even in patients with expanded criteria, partial liver resection can contribute to a prolonged survival and even cure. With expansion of the criteria for liver resection, the limits of liver surgery were reached and additional measurements became necessary to render patients tumor free. Thermoablation is one of these additional techniques, and it is nowadays widely applied. Radiofrequency ablation (RFA) is a technique which is based on the conversion of electromagnetic energy into heat. It is in use for destruction of tumors in various organs. It is a useful adjunct to partial liver resection and offers the opportunity to cure patients with liver tumors who cannot be cured by partial liver resection. The application of RFA expanded the armamentarium of intentionally curative treatment modalities. The aim of this paper is to briefly summarize the place of ablation of liver tumors in daily clinical practice and to make the point that it is an adjunct in the multimodality treatment of liver tumors nowadays.

\section{Historical Overview}

The first publication on application of radiofrequency-based ablation of liver (in animals) appeared in 1961 [1]. The unraveling of the effects of electromagnetic fields on organisms can be attributed to the physician and physicist Jacques d'Arsonval (1851-1940). He worked as an assistant of the famous physiologist Claude Bernard (18131878 ) and was mainly interested in the physiological effects of application of electromagnetic fields to living organisms [2]. In 1891, he demonstrated that alternating current with a frequency higher than $10,000 \mathrm{~Hz}$ could be applied in living organisms without causing pain or neuromuscular contractions [3]. He was honored for his investigations by introducing the term 'darsonvalization' - the application of alternating current in medicine. His contributions also resulted in the installation of the 'd'Arsonval award' by the Bioelectromagnetic Society for investigators with 'extraordinary accomplishment within the discipline of bioelectromagnetics'. A brief biography of d'Arsonval is available at http://profiles.incrediblepeople.com/jacques-arsene-darsonval/.

\section{Methods for Local Tumor Destruction}

Several methods for local destruction of liver tumors are used [4]. Tumor destruction can be performed by physical means, like heat or cold, by chemical methods such as alcohol injection in the tumor, or by application of ionizing radiation. Tumor destruction by repeated freeze-thaw cycles is performed via the insertion of hollow probes through which liquid nitrogen is pumped. This approach - cryosurgical ablation - is used for the treatment of renal and liver tumors [5-7]. Alcohol injection is often used for hepatocellular carcinoma (HCC), and although it has been demonstrated to be less effective than thermoablation [8], the associated costs are far less than with thermoablation. High-intensity focused ultrasound is based on the conversion of the energy of acoustic waves into heat, and has the advantage of being completely noninvasive [9]. Stereotactic body radiotherapy and injection of radioactive microspheres into the hepatic artery supplying the liver tumor are examples of the application of electromagnetic waves that induce tumor necrosis via ionizing radiation $[10,11]$. RFA and microwave ablation (MWA) are probably the most widely applied thermoablative techniques for the treatment of liver tumors, and both are examples of the application of non-ionizing electromagnetic waves in humans.

\section{Principles of Electromagnetic Fields}

Electromagnetic waves are characterized by the three physical properties wavelength, frequency or photon energy. Photon energy and frequency are directly proportional, and thus the low-frequency radiowaves contain low energy and - at the other end of the spectrum - gamma rays have the highest energy (fig. 1). For ablation of liver tumors, both RFA and (more recently) MWA are applied. MWA has a higher frequency range than RFA, and thus the amount of energy transmitted to tissues is accordingly higher. Water molecules are dipoles, and the alternating electromagnetic field of microwaves forces the water molecules to align with the changing electromagnetic field. This forced movement creates the increase in temperature. The high water content of tissues and cells contributes to the heating effect of MWA. MWA has some advantages over RFA; it is faster and able to ablate larger volumes, it is less influenced by adjacent structures like vessels, which tempt to transport the heat away; it has a direct heating effect, whereas the heating of RFA is dependent on thermal conduction to areas remote from the inserted needle, and finally grounding pads are not necessary. A more detailed description of microwave principles is given by Brace [12]. 


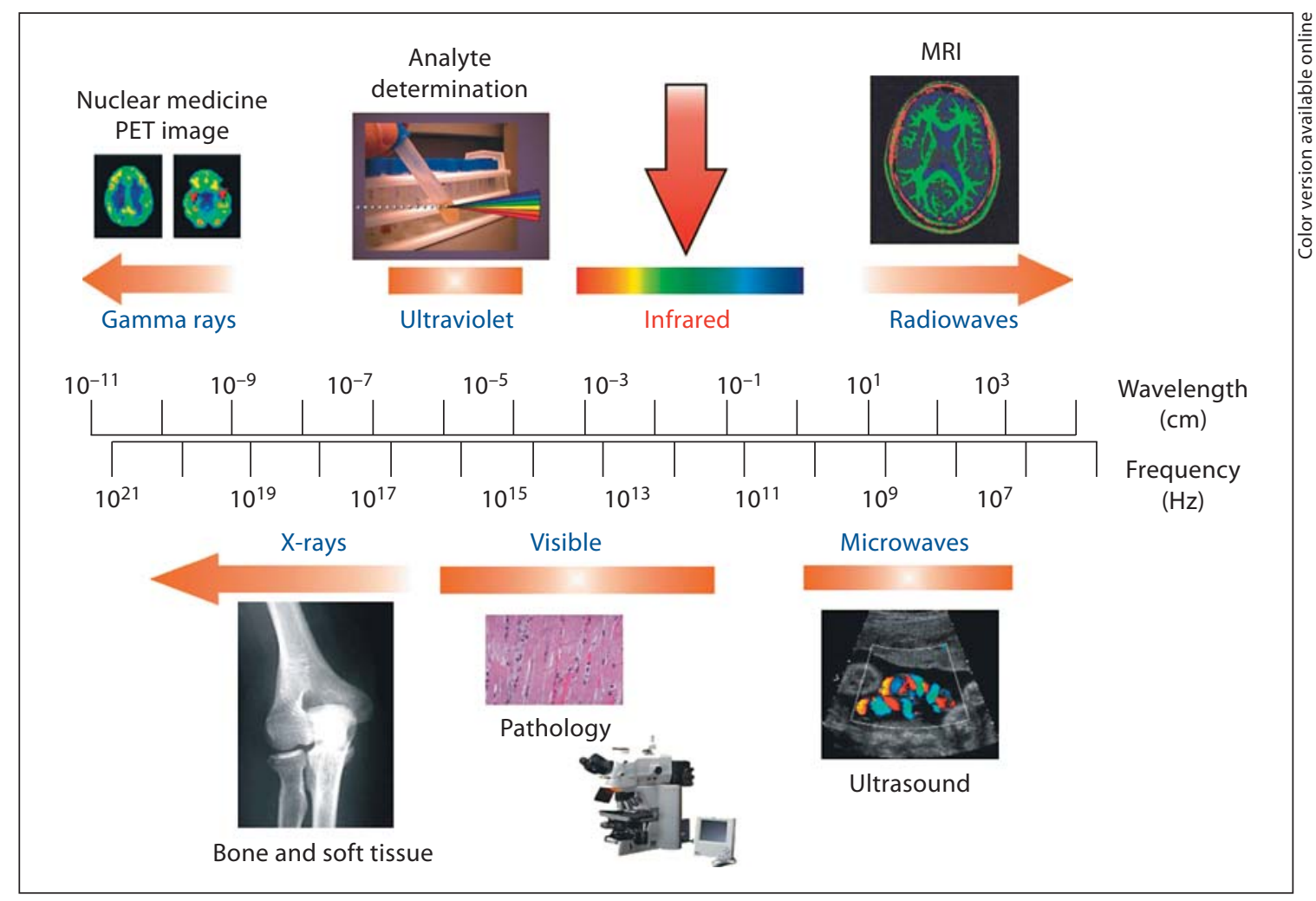

Fig. 1. The electromagnetic spectrum. (Picture obtained from Hynes et al., BMC Med Imaging 2005;5:2.)

\section{Indications for Thermoablation of Liver Tumors}

The indications for ablation of liver tumors can be categorized as shown in table 1 .

\section{Unresectable Liver Tumors}

Liver tumors can be unresectable because of severe underlying parenchymal abnormalities which limit the extent of the liver resection or because partial liver resection is not able to render the patient tumor free. This for instance is the case in patients with bilobar colorectal liver metastases. Basically, for this problem two solutions exist; one is the combination of partial liver resection with local ablation, and the other is to perform a twostage resection [13-15]. Although evidence is lacking to make a rational decision, we advocate the policy to try to make the patient tumor free in one operation consisting of resection and ablation. The advantages are evident: (1) an intentionally curative procedure has been performed in one operation, (2) progressive outgrowth of the remaining liver metastases during ensuing liver regeneration is not a threat, (3) procedure-related morbidity oc- curs only once, (4) ablation is associated with a low chance of complications, and, last but not least, (5) if an ablation site recurrence occurs, the patient can be scheduled for an additional resection or local ablation. Especially relevant in this respect is that indeed ablation of liver tumors is a low-risk procedure $[16,17]$. An additional argument is that several processes, including liver regeneration and the inflammatory response, associated with recovery after a surgical procedure might contribute to accelerated tumor growth of remaining vital tumors [18-21]. Based on measurements of serum growth factors, we demonstrated that laparotomy alone can induce this response and thereby could possibly contribute to enhanced tumor growth $[22,23]$. In the aforementioned series, about $25 \%$ of the patients did not undergo the second stage hepatectomy because of disease progression after the first hepatectomy [13-15]. Thus, all efforts should be made to make a patient tumor free in one operation and not wait for a second procedure by leaving behind vital tumor which could 'benefit' from the prosperous, tumor growth-promoting circumstances after a surgical procedure. 
Table 1. Indications for application of RFA

\begin{tabular}{|c|c|}
\hline Indication & Examples \\
\hline $\begin{array}{l}\text { Partial liver resection } \\
\text { impossible }\end{array}$ & $\begin{array}{l}\text { Insufficient functional future liver } \\
\text { remnant } \\
\text { - Unfavorable liver anatomy } \\
\text { - Cirrhosis } \\
\text { - Severe steatosis } \\
\text { - 'Blue liver syndrome' } \\
\text { - Previous liver resection }\end{array}$ \\
\hline $\begin{array}{l}\text { Liver not tumor free after } \\
\text { partial resection }\end{array}$ & Bilobar disease \\
\hline $\begin{array}{l}\text { Need for simultaneous } \\
\text { major abdominal procedure }\end{array}$ & $\begin{array}{l}\text { Synchronous liver metastases with } \\
\text { primary tumor still in situ }\end{array}$ \\
\hline $\begin{array}{l}\text { Bridging therapy to } \\
\text { additional treatment }\end{array}$ & $\begin{array}{l}\text { HCC with planned liver } \\
\text { transplantation } \\
\text { Simultaneous with portal vein } \\
\text { embolization }\end{array}$ \\
\hline $\begin{array}{l}\text { Debulking of symptomatic } \\
\text { liver tumor }\end{array}$ & $\begin{array}{l}\text { Neuroendocrine liver metastases } \\
\text { Liver metastases medullary } \\
\text { thyroid cancer }\end{array}$ \\
\hline $\begin{array}{l}\text { Dose reduction of other po- } \\
\text { tentially toxic therapies }\end{array}$ & Liver metastases of thyroid cancer \\
\hline $\begin{array}{l}\text { Patient unfit or unwilling to } \\
\text { undergo major operation }\end{array}$ & Cardiopulmonary comorbidity \\
\hline
\end{tabular}

The other patient category with unresectable liver tumors consists of patients with severe underlying liver disease, most often patients with liver cirrhosis and HCC. In a recent systematic review, it was concluded that RFA (1) is the first-line treatment for patients with unresectable, small $(<5 \mathrm{~cm})$ HCCs who are not transplant candidates, (2) is an alternative for resection in patients with $\mathrm{HCC}<3$ $\mathrm{cm}$, and (3) is promising in recurrent and unresectable HCC [24]. In the US, the number of RFA procedures for HCC treatment increased over time with a more or less simultaneous decrease in the number of liver resections [25]. Firm conclusions on the type of patients who underwent RFA (for instance previously deemed unresectable and now treated with RFA or previously considered resectable but as a replacement now treated with RFA) which explain these shifts cannot be drawn from this study. Nevertheless, the study is important in that it shows that RFA is more liberally applied in patients with HCC.

Need for a Simultaneous Major Abdominal Procedure

Another indication for ablation instead of an extended liver resection can be in patients with synchronous liver metastases in whom the primary tumor is still present. In several publications, it was shown that simultaneous bowel resection and partial hepatectomy can be performed with a comparable morbidity and mortality as with staged separate procedures for the colon resection and hepatectomy $[26,27]$. Of note, in both reports RFA was applied in a substantial number of patients. Reddy et al. [26] found an increased complication rate if colonic resection was combined with a major hepatectomy, and they considered this only in highly selected patients. When performing simultaneous extensive liver surgery and resection of the primary colorectal cancer, it is our policy to have a low threshold to give the patient a (temporary) colostomy. The aim of this policy is to prevent anastomotic leakage, which can be disastrous in a patient with a small liver remnant.

Patients with rectal carcinoma presenting with simultaneous liver metastases might be a special category because combining a low anterior resection or an abdominal perineal resection together with a partial liver resection might indeed be too much for the elderly patient. In those cases, we advocate partial hepatectomy with a liberal use of local ablation of the liver metastases with resection of the rectal carcinoma, a policy with an acceptable low risk [28].

\section{Ablation as a Bridging Therapy}

Ablation was shown to be effective in patients with HCC waiting for liver transplantation. The main advantage of this approach is that progression of the HCC during the waiting time for transplantation is halted and thereby drop out of patients from the waiting list because of tumor progression beyond transplantation criteria can be prevented [24]. Application of RFA as a first step in patients who are transplant candidates offers another great advantage. During the waiting time, the biological behavior of the disease can be judged, and patients with highly aggressive tumors can be identified. This so called 'ablate and wait' policy will likely prevent futile liver transplantations in patients with a high chance of early recurrences after transplantation [29]. This strategy sounds reasonable, especially in patients with more advanced HCC and who fulfill the expanded criteria for transplantation.

A comparable indication is for patients in whom portal vein embolization is foreseen in order to increase the future liver remnant in size. This intervention is a safe and effective method to induce atrophy of the embolized part of the liver (the right liver lobe) with a concomitant increase in size of the future liver remnant (the left liver 
lobe) [30]. In several studies, it was demonstrated that tumors in the regenerating left liver lobe - after embolization of the right portal vein - also demonstrate enhanced growth, sometimes even at a higher growth rate than the liver lobe itself $[31,32]$. This can be prevented by simultaneous ablation of the tumor in the left liver lobe. It is our policy to first perform a CT-guided ablation of the tumor in the left liver lobe and a portal vein embolization the day after. Depending on the location of the ablated tumor and the size of the future remnant liver, either the ablated tumor can be resected together with the right liver lobe or it can be left in place. A thorough follow-up of the ablated tumor is then necessary to detect and treat an ablation site recurrence.

\section{Debulking to Reduce Symptoms or Side Effects of}

Other Therapies

Ablation can cause significant symptomatic relief in patients with hormonally active tumors which give rise to debilitating symptoms. Examples are patients with liver metastases from neuroendocrine tumors or from medullary thyroid carcinoma [33-36]. The latter can have severe diarrhea possibly related to excess calcitonin production by the liver metastases. Also, patients with metastatic thyroid carcinoma and dose-related side effects because of repeated cumulative toxic ${ }^{131}$ I treatments can benefit from debulking by thermoablation of liver metastases; the subsequent dose of radioactive iodine can be reduced [35, 37].

\section{Comorbidity}

Finally, patients with severe comorbidities in whom the risks of partial liver resection are judged to be too high should be offered the possibility of a minimally invasive procedure such as percutaneous ablation.

\section{Results of Combining Ablation with Partial Liver Resection}

In a recent systematic review of reported series on the combination of RFA with liver resection, 3- and 5-year survival rates of 45 and $30 \%$ for patients with colorectal liver metastases were reported [38]. Several single-institutional series report variable results with respect to survival in patients with colorectal liver metastases treated with RFA as compared to partial hepatectomy, but patient selection in these series has a great impact [39-42]. Currently, no randomized trials on resection versus ablation for colorectal metastases are present, and thus we have to base our decisions on published series on the subject. It is beyond any doubt that patients treated with RFA and resection is a negative selection; these patients have multiple tumors, bilobar disease or recurrences after previous liver surgery. All these characteristics are adverse risk factors for survival [40]. Despite this bias, survival results are in the same order of magnitude as those obtained in populations of patients with colorectal liver metastases treated by partial hepatectomy. And even more important, the combination of RFA and liver resection seems to be associated with a better survival as compared to salvage chemotherapy for patients who are found to have unresectable and/or unablatable tumors.

\section{Limitations of Local Ablation}

Despite the achievements obtained with ablation of liver tumors, substantial improvements are still needed. One of the major disadvantages of RFA is the incidence of ablation site recurrences. Although the reported incidence is highly variable, numbers of up to $60 \%$ can be found in the literature, and this is clearly unacceptably high [43].

Ablation tract metastases are reported with a median incidence of $0.6 \%$ (range $0-5.5 \%$ ) in patients with HCC treated with RFA [44]. This complication has only very rarely been described in patients with colorectal liver metastases after RFA treatment [45]. It is advised to puncture a tumor always through a rim of adjacent liver tissue; this is especially important in subcapsular tumors in which the risk of tumor spill seems to be especially high. RFA of tumors in close proximity of bile ducts should be performed with great caution because of the risk of irreversible damage to the bile ducts. RFA should not be performed in patients with bilioenteric anastomosis because bacterial contamination of the bile ducts predisposes to the development of infected necrotic tissue in the liver which can sometimes be rather resistant to conventional drainage techniques [46].

\section{Conclusions}

RFA is a procedure with a low complication rate and is applied in many centers for various - and progressively expanding - indications. RFA is already accepted as an alternative for treatment of (small) HCC. Nowadays, for the treatment of colorectal liver metastases several modalities should be considered to increase the number of 
potentially curable patients [47]. Many centers consider ablation as one of these modalities. The major limitation is its lack of evidence because well designed and sufficiently powered randomized studies are not available [48]. The limitations of ablation with radiofrequent waves seem to be circumvented by MWA. Therefore, randomized trials in which ablation is compared to partial liver resection should be performed with MWA as the ablation modality of choice. Because many centers have already incorporated ablation as a treatment strategy and the rather good results of RFA, it is questionable whether these randomized studies will ever be performed.

\section{Disclosure Statement}

The authors declare that they have no conflicts of interest.

\section{References}

$\rightarrow 1$ Lounsberry W, Goldschmidt V, Linke CA, Walder HJ, Chrzan D: The early histologic changes following electrocoagulation. J Urol 1961;86:321-329.

-2 Geddes LA: Retrospectroscope. d'Arsonval, physician and inventor. IEEE Eng Med Biol Mag 1999;18:118-122.

3 d'Arsonval MA: Action physiologigue des courants alternatifs. CR Soc Biol 1891;283286.

4 Bhardwaj N, Strickland AD, Ahmad F, Dennison AR, Lloyd DM: Liver ablation techniques: a review. Surg Endosc 2010;24:254265.

5 Kunkle DA, Uzzo RG: Cryoablation or radiofrequency ablation of the small renal mass: a meta-analysis. Cancer 2008;113:2671-2680.

-6 Seifert JK, Springer A, Baier P, Junginger T: Liver resection or cryotherapy for colorectal liver metastases: a prospective case control study. Int J Colorectal Dis 2005;20:507-520.

7 Xu KC, Niu LZ, He WB, Hu YZ, Zuo JS: Percutaneous cryosurgery for the treatment of hepatic colorectal metastases. World J Gastroenterol 2008; 14:1430-1436.

-8 Cho YK, Kim JK, Kim MY, Rhim H, Han JK: Systematic review of randomized trials for hepatocellular carcinoma treated with percutaneous ablation therapies. Hepatology 2009;49:453-459.

9 Fischer K, Gedroyc W, Jolesz FA: Focused ultrasound as a local therapy for liver cancer. Cancer J 2010;16:118-124.

10 Dawood O, Mahadevan A, Goodman KA: Stereotactic body radiation therapy for liver metastases. Eur J Cancer 2009;45:2947-2959.

-11 Ahmadzadehfar H, Biersack HJ, Ezziddin S: Radioembolization of liver tumors with yttrium-90 microspheres. Semin Nucl Med 2010;40:105-121.

12 Brace CL: Microwave ablation technology: what every user should know. Curr Probl Diagn Radiol 2009;38:61-67.

13 Wicherts DA, Miller R, de Haas RJ, Bitsakou G, Vibert E, Veilhan LA, Azoulay D, Bismuth $\mathrm{H}$, Castaing D, Adam R: Long-term results of two-stage hepatectomy for irresectable colorectal cancer liver metastases. Ann Surg 2008;248:994-1005.
14 Karoui M, Vigano L, Goyer P, Ferrero A, Luciani A, Aglietta M, Delbaldo C, Cirillo S, Capussotti L, Cherqui D: Combined firststage hepatectomy and colorectal resection in a two-stage hepatectomy strategy for bilobar synchronous liver metastases. Br J Surg 2010;97:1354-1362.

15 Tsai S, Marques HP, de Jong MC, Mira P, Ribeiro V, Choti MA, Schulick RD, Barroso E, Pawlik TM: Two-stage strategy for patients with extensive bilateral colorectal liver metastases. HPB (Oxford) 2010;12:262-269.

16 De Baere T, Risse O, Kuoch V, Dromain C, Sengel C, Smayra T, Gamal El Din M, Letoublon C, Elias D: Adverse events during radiofrequency treatment of 582 hepatic tumors. AJR Am J Roentgenol 2003;181:695-700.

17 Garrean S, Hering J, Saied A, Helton WS, Espat NJ: Radiofrequency ablation of primary and metastatic liver tumors: a critical review of the literature. Am J Surg 2008; 195:508520.

18 de Jong KP, Lont HE, Bijma AM, van Veen ML, Brouwers MAM, de Vries EGE, Marquet RL, Slooff MJH, Terpstra OT: The effect of partial hepatectomy on tumor growth in rats. In vivo and in vitro studies. Hepatology 1995;22:1263-1272.

19 Auguste P, Fallavollita L, Wang N, Burnier J, Bikfalvi A, Brodt P: The host inflammatory response promotes liver metastasis by increasing tumor cell arrest and extravasation. Am J Pathol 2007;170:1781-1792.

20 van der Bij GJ, Oosterling SJ, Beelen RH, Meijer S, Coffey JC, van Egmond M: The perioperative period is an underutilized window of therapeutic opportunity in patients with colorectal cancer. Ann Surg 2009; 249:727-734

21 de Jong KP, Slooff MJH, de Vries EGE, Brouwers MAM, Terpstra OT: Effect of partial liver resection on tumour growth. J Hepatol 1996;25:109-121.
22 de Jong KP, Alting von Geusau B, Rottier CA, Bijzet J, Limburg PC, de Vries EGE, Fidler V, Slooff MJH: Serum response of hepatocyte growth factor, insulin-like growth factor-I, interleukin-6, and acute phase proteins in patients with colorectal liver metastases treated with partial hepatectomy or cryosurgery. J Hepatol 2001;34:422-427.

23 de Jong KP, Hoedemakers RMJ, Fidler V, Bijzet J, Limburg PC, Peeters PMJG, de Vries EGE, Slooff MJH: Portal and systemic serum growth factor and acute phase response after laparotomy or partial hepatectomy in patients with colorectal liver metastases: a prognostic role for $\mathrm{C}$-reactive protein and hepatocyte growth factor. Scand J Gastroenterol 2004;39:1141-1148.

24 Lau WY, Lai EC: The current role of radiofrequency ablation in the management of hepatocellular carcinoma: a systematic review. Ann Surg 2009;249:20-25.

25 Massarweh NN, Park JO, Farjah F, Yeung RS, Symons RG, Vaughan TL, Baldwin LM, Flum DR: Trends in the utilization and impact of radiofrequency ablation for hepatocellular carcinoma. J Am Coll Surg 2010;210: 441-448.

26 Reddy SK, Pawlik TM, Zorzi D, Gleisner AL, Ribero D, Assumpcao L, Barbas AS, Abdalla EK, Choti MA, Vauthey JN, Ludwig KA, Mantyh CR, Morse MA, Clary BM: Simultaneous resections of colorectal cancer and synchronous liver metastases: a multi-institutional analysis. Ann Surg Oncol 2007;14:3481-3491.

27 Martin RC, Augenstein V, Reuter NP, Scoggins CR, McMasters KM: Simultaneous versus staged resection for synchronous colorectal cancer liver metastases. J Am Coll Surg 2009;208:842-850.

28 Van Dijk TH, Hospers GAP, Beukema JC, Beets GL, Gelderblom AJ, de Jong KP, Rutten HJ, Van de Velde CJH, Wiggers T, Havenga $\mathrm{K}$ : Short-course radiation therapy, neoadjuvant bevacizumab, capecitabine and oxaliplatin, and radical resection of primary tumour and metastases in primary stage IV rectal cancer: a phase II multicenter study of the Dutch Colorectal Cancer Group. Ann Oncol 2010;21:I51. 
29 Roberts JP, Venook A, Kerlan R, Yao F: Hepatocellular carcinoma: ablate and wait versus rapid transplantation. Liver Transpl 2010;16:925-929.

-30 Abulkhir A, Limongelli P, Healey AJ, Damrah O, Tait P, Jackson J, Habib N, Jiao LR: Preoperative portal vein embolization for major liver resection: a meta-analysis. Ann Surg 2008;247:49-57.

31 Pamecha V, Levene A, Grillo F, Woodward N, Dhillon A, Davidson BR: Effect of portal vein embolisation on the growth rate of colorectal liver metastases. Br J Cancer 2009, 100:617-622.

32 de Graaf W, van den Esschert JW, van Lienden KP, van Gulik TM: Induction of tumor growth after preoperative portal vein embolization: is it a real problem? Ann Surg Oncol 2009; 16:423-430.

-33 Mayo SC, de Jong MC, Pulitano C, Clary BM, Reddy SK, Gamblin TC, Celinksi SA, Kooby DA, Staley CA, Stokes JB, Chu CK, Ferrero A, Schulick RD, Choti MA, Mentha G, Strub J, Bauer TW, Adams RB, Aldrighetti L, Capussotti L, Pawlik TM: Surgical management of hepatic neuroendocrine tumor metastasis: results from an international multiinstitutional analysis. Ann Surg Oncol 2010; 17:3129-3136.

34 Maithel SK, Fong Y: Hepatic ablation for neuroendocrine tumor metastases. J Surg Oncol 2009;100:635-638.

-35 Wertenbroek MW, Links TP, Prins TR, Plukker JT, van der Jagt EJ, de Jong KP: Radiofrequency ablation of hepatic metastases from thyroid carcinoma. Thyroid 2008;18:11051110 .
36 Kloos RT, Eng C, Evans DB, Francis GL, Gagel RF, Gharib H, Moley JF, Pacini F, Ringel MD, Schlumberger M, Wells SA Jr: Medullary thyroid cancer: management guidelines of the American Thyroid Association. Thyroid 2009; 19:565-612.

37 Rubino C, De VF, Dottorini ME, Hall P, Schvartz C, Couette JE, Dondon MG, Abbas MT, Langlois C, Schlumberger M: Second primary malignancies in thyroid cancer patients. Br J Cancer 2003;89:1638-1644.

38 Eisele RM, Zhukowa J, Chopra S, Schmidt SC, Neumann U, Pratschke J, Schumacher G: Results of liver resection in combination with radiofrequency ablation for hepatic malignancies. Eur J Surg Oncol 2010;36:269274.

39 Abdalla EK, Vauthey JN, Ellis LM, Ellis V, Pollock R, Broglio KR, Hess K, Curley SA: Recurrence and outcomes following hepatic resection, radiofrequency ablation, and combined resection/ablation for colorecta liver metastases. Ann Surg 2004;239:818825 .

40 Nikfarjam M, Shereef S, Kimchi ET, Gusani NJ, Jiang Y, Avella DM, Mahraj RP, StaveleyO'Carroll KF: Survival outcomes of patients with colorectal liver metastases following hepatic resection or ablation in the era of effective chemotherapy. Ann Surg Oncol 2009; 16:1860-1867.

41 Berber E, Tsinberg M, Tellioglu G, Simpfendorfer $\mathrm{CH}$, Siperstein AE: Resection versus laparoscopic radiofrequency thermal ablation of solitary colorectal liver metastasis. J Gastrointest Surg 2008;12:1967-1972.

42 Siperstein AE, Berber E, Ballem N, Parikh RT: Survival after radiofrequency ablation of colorectal liver metastases: 10-year experience. Ann Surg 2007;246:559-565.
43 Mulier S, Ni Y, Jamart J, Ruers T, Marchal G, Michel L: Local recurrence after hepatic radiofrequency coagulation: multivariate meta-analysis and review of contributing factors. Ann Surg 2005;242:158-171.

44 Stigliano R, Marelli L, Yu D, Davies N, Patch $\mathrm{D}$, Burroughs AK: Seeding following percutaneous diagnostic and therapeutic approaches for hepatocellular carcinoma. What is the risk and the outcome? Seeding risk for percutaneous approach of HCC. Cancer Treat Rev 2007;33:437-447.

45 Liu SY, Lee KF, Lai PB: Needle track seeding: a real hazard after percutaneous radiofrequency ablation for colorectal liver metastasis. World J Gastroenterol 2009;15:16531655 .

46 de Jong KP, Prins TR, Hofker HS: A new in terventional technique for percutaneous treatment of drainage-resistant liver abscess. Br J Radiol 2010;83:e195-e197.

$\checkmark 47$ de Jong KP: Review article: multimodality treatment of liver metastases increases suitability for surgical treatment. Aliment Pharmacol Ther 2007;26:161-169.

48 Wong SL, Mangu PB, Choti MA, Crocenzi TS, Dodd GD III, Dorfman GS, Eng C, Fong Y, Giusti AF, Lu D, Marsland TA, Michelson R, Poston GJ, Schrag D, Seidenfeld J, Benson AB III: American Society of Clinical Oncology 2009 clinical evidence review on radiofrequency ablation of hepatic metastases from colorectal cancer. J Clin Oncol 2010;28: 493-508. 